\title{
Review on the Preparation, Structure and Property Relation of Clay-Based Polymer Nanocomposites
}

\author{
David P. Penaloza, Jr.* \\ Chemistry Department, College of Science, De La Salle University, Manila
}

\begin{abstract}
Clay-based polymer nanocomposites have attracted considerable interest in recent years because of the intermarriage between organic and clay components at nanoscale measurement offers prospect of new and enhanced properties. Resulting nanomaterials are of practical importance in applications that require exceptional mechanical properties, remarkable thermal stability, and good barrier properties. This review paper highlights the benefits we can derive from the preparation of these nanomaterials.
\end{abstract}

Keywords: clay-polymer nanocomposite; montmorillonite; exfoliation; clay modification

\section{INTRODUCTION}

This article discusses the different remarkable property enhancements observed in clay-based polymer nanocomposite systems obtained through the clay incorporation in various polymeric materials since an exfoliated clay-polymer nanohybrid material was first reported by the Toyota researchers in the 1980s.

Clay-based polymer nanocomposites are a class of inorganic-organic hybrids having a polymer matrix reinforced with a small loading $(<10 \%)$ of nanometricsized clay platelets (Giannelis, 1996; Ogasa et al., 1995; Ogawa and Kuroda, 1997; Alexandre et al., One-pot, 2001; Fu and Qutubuddin, 2001; Song et al., 2015; Unuabonah and Taubert, 2014; Lambert and Bergaya, 2013; Bergaya et al., 2013; Kim and Palomino, 2011; Wang and Pinnavaia, 1994). The term nanocomposite refers to a combination of two or more materials where one of the phases has one, two or three dimensions within the nanometer $\left(10^{-9} \mathrm{~m}\right)$ range (Goldstein, 1997). Due to the small size and the high surface-to-volume ratio of the inorganic filler at this length scale, the polymer nanocomposites have exhibited remarkable property enhancements and new properties compared to their unfilled polymer and conventional composites. The reinforcing material having at least one dimension in the nanometer length scale can be made up of particles, sheets or fibers. In the case of a claybased polymer nanocomposite, the inorganic phase is a layered silicate clay. It has a layered structure consisting of stacks of silica platelets each having a thickness of about one nanometer.

In most polymer-clay nanocomposites, the most preferred material as a filler is montmorillonite (MMT) owing to its layered structure and rich intercalation chemistry (Osman et al., 2017; Martino et al., 2017; Chen et al., Quaternized, 2017; Hajibeygi et al., 2016; Penaloza et al., 2015; Marchante and Beltrán, 2015; Spoljaric et al., 2014; Valandro et al., 2013; Schauberger et al., 2013). An individual clay platelet in an MMT clay structure is about one nanometer thick. The goal is to fully exfoliate these platelets into several individual sheets leading to a well-dispersed and random orientation in the organic phase (Figure 1). 


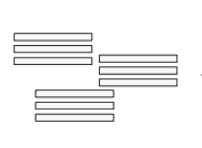

layered silicates

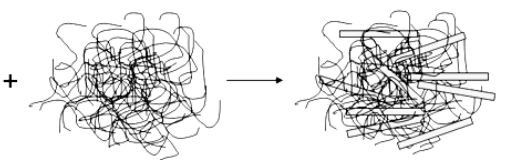

polymer clay-polymer nanocomposite

Figure 1. A clay-based polymer nanocomposite is an inorganic-organic hybrid material where the nanometer thick individual silicate platelets of the clay inorganic phase are homogeneously dispersed in an organic polymer matrix. Even at a low clay loading results in new and improved properties of the nanocomposite. (Usuki et al., Synthesis, 1993; Usuki et al., Swelling, 1993)

\section{PIONEERING WORK OF TOYOTA}

Polymer nanocomposites based on silicate clays were first observed by the Toyota's Central Research and Development Laboratories in the 1980s in which a low amount of a modified montmorillonite (MMT) clay incorporated into a nylon 6 matrix dramatically improved the physical properties of the nylon-clay hybrid $(\mathrm{NCH})$ in comparison to an unfilled nylon 6 polymer (Okada and Usuki, 1995; Kawasumi, 2004; Kojima et al., 1994; Usuki et al., Interaction, 1995; Usuki et al., Synthesis, 1995).

By replacing cations in the galleries of the MMT clay with alkyl ammonium ions (Figure 2), the Toyota researchers were able to swell the clay and polymerize $\varepsilon$-caprolactam into the galleries of the MMT clay filler to produce a nylon-clay nanocomposite that exhibits remarkable physical property improvements.

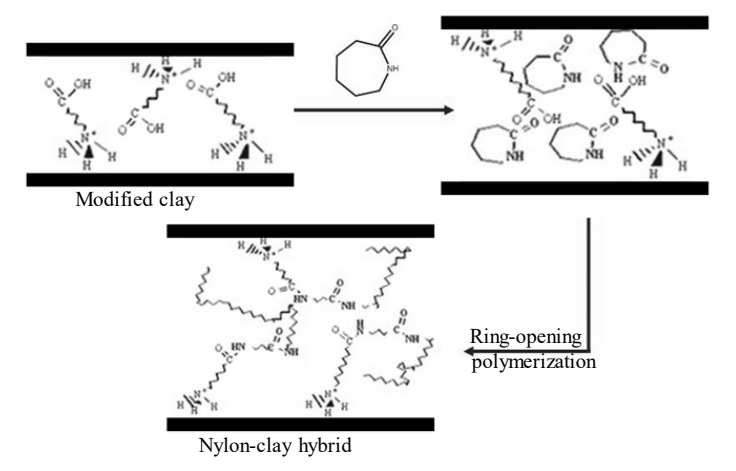

Figure 2. In situ Polymerization of the $\varepsilon$-Caprolactone Monomer Initiated by the -COOH Groups of the Alkyl Ammonium Salts Used to Modify the Surface of a Montmorillonite Clay to Produce Nylon-clay Hybrids (NCHs) (Usuki et al., Synthesis, 1993; Usuki et al., Swelling, 1993).

The hybrid nanomaterial containing only a very small amount of clay exhibited a modulus that more than doubled and a tensile strength that was enhanced by as much $50 \%$ relative to the unfilled nylon 6. The heat distortion temperature of the nanocomposite was increased from $65^{\circ} \mathrm{C}$ to 152 ${ }^{\circ} \mathrm{C}$, at 5\% loading (Figure 3) (Kojima et al., 1994; Usuki et al., Polymer-clay, 2005).
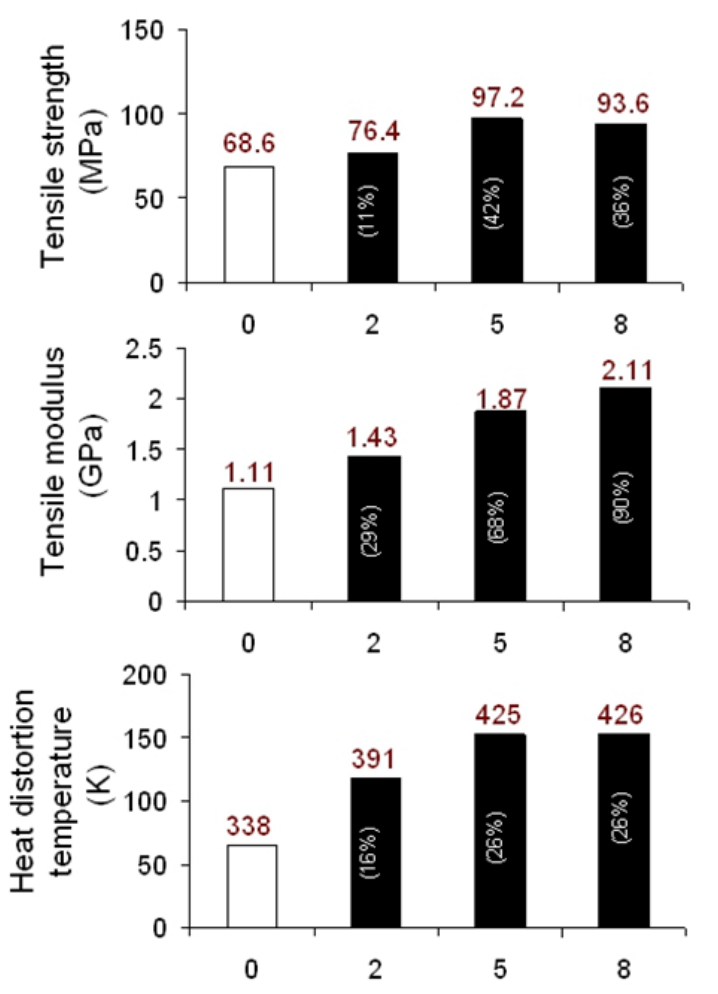

Clay content, \%

Figure 3. Property Enhancements Measured by the Toyota Researchers in Terms of Increased Tensile Modulus and Strength as well as Improved Heat Distortion Temperature of the Nylon-clay Hybrids (NCH) Compared to the Pure Nylon 6 Polymer (Usuki et al., Synthesis, 1993; Usuki et al., Swelling, 1993; Okada and Usuki, Twenty, 2006).

The polymerization of the caprolactam is initiated from the carboxylic acid groups of the alkyl ammonium cations ionically tethered to the MMT clay. The growing polymer chains forced the silicate layers far apart creating a nanocomposite where they observed individually dispersed MMT platelets homogeneously distributed in the nylon 6 matrix. With this technique, polymer chains are tethered to the surface of the silicate filler through ionic interactions between the negatively charged silicate surface and the positively charged ammonium cation located at one end of the polymer chain.

The observed property enhancements of these nanocomposite materials do not only depend on the properties of the clay filler and the nylon matrix but also on their morphology and interfacial characteristics. To determine the morphology of the silicate clay in the nanocomposite, transmission electron microscopy (TEM) and scanning electronic 
microscopy (SEM) were used. The TEM and SEM images of the nanocomposites showed that the clay is exfoliated.

\section{CLAY-POLYMER INTERACTION}

There are three possible morphologies when a clay filler and a polymer interact-conventional composite, intercalated and exfoliated (Figure 4). In a conventional composite (Kornmann et al., 2001; Bledzki and Gassan, 1999; Hedenberg and Gatenholm, 1995; Eichhorn et al., 2001; Rong et al., 2001), the clay stacking remains the same due to the inability of the polymer chains to enter between the clay galleries. The clay exists as aggregates and there is little to no interaction between the clay and the polymer. In an intercalated (Lee and Jang, Preparation, 1996; Noh and Lee, 1999; Lee and Jang, Characterization, 1998; Vaia et al., New, 1995; Szymczyk et al., 2013; Shakoor et al., 2012; Hong and Rhim, 2012) structure, there is clay swelling due to the polymer chains being able to insert between the clay galleries. This is characterized by the increase in the interlayer spacing of the clay layered structure. When the clay platelets are fully delaminated from the original stacking and are well dispersed and randomly oriented in a continuous polymer matrix, an exfoliated structure is achieved (Penaloza et al., 2015; Kornmann et al., 2001; Fischer et al., 1999; Strawhecker and Manias, 2000; Moustafa et al., 2017; Marques and Fernandes, 2017; Swaminathan and Shivakumar, 2011). The exfoliated structure is thought to yield the maximum enhancement of physical properties.

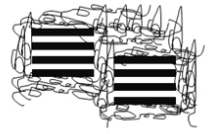

Microcomposite
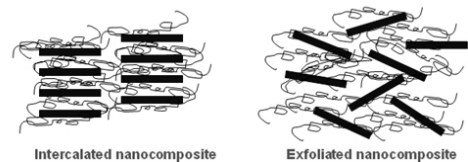

Figure 4. Three Types of Clay-polymer Interaction: Microcomposite, where the Clay Fillers Exist as Aggregates in the Polymer Matrix; Intercalated, where Chains are Found between Clay Platelets and Results in Increased Gaps between Clay Platelets and Exfoliated, which Show Full Delamination of the Clay Layered Structure and Individual Nanometer-thick Platelets are Randomly Dispersed in the Bulk Polymer (Alexandre and Dubois, Polymer-layered, 2000).

$\mathrm{X}$-ray diffraction $(\mathrm{XRD})$ and transmission electron microscopy (TEM) are usually employed in studying the morphology of the clay fillers in nanocomposites. An XRD plot of a silicate clay having an intercalated structure in a nanocomposite will have the (001) characteristic peak shifted at a lower angle due to the expansion of the space gaps between platelets. Although the layer spacing increases, there still exists an attractive force among the silicate layers to stack them in an ordered structure. In contrast, no peaks are observed in the XRD pattern of an exfoliated claybased polymer nanocomposite due to the loss of the structural registry of the clay layers. The absence of Bragg diffraction peaks in the nanocomposites may indicate that the clay has been completely exfoliated or delaminated as shown in Figure 5. Results from an XRD measurement to establish whether the clay structure is either intercalated and/or exfoliated is further substantiated with TEM images of the nanocomposites. TEM can provide useful information in a localized area on the morphology, structure and spatial distribution of the dispersed phase of the nanocomposites. Hence, in establishing whether the inorganic clay phase of a nanocomposite exists either as intercalated or exfoliated, XRD and TEM are used as complementary characterization techniques.

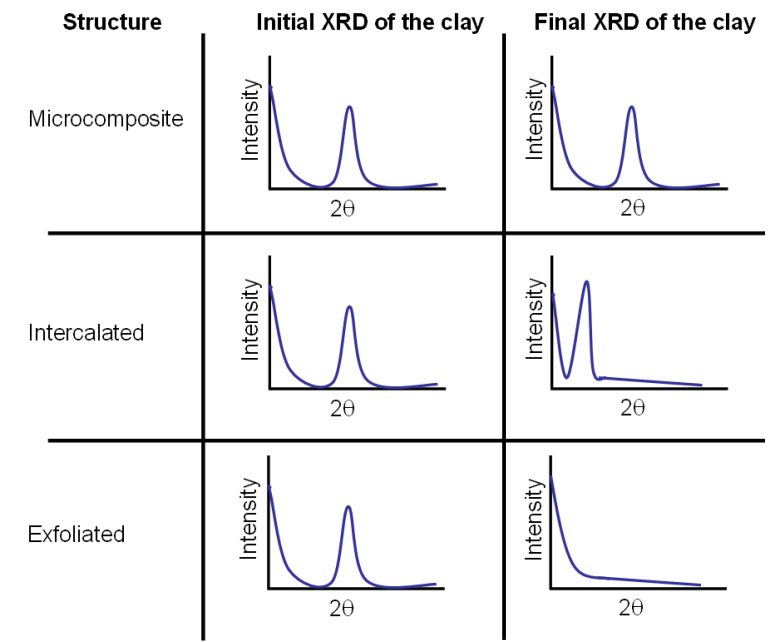

Figure 5. Representative XRD Plot of a Nanocomposite System where the Clay Filler Can Exist in a Polymer Matrix either as Aggregates (microcomposite); Intercalated or Exfoliated Structure (Vaia and Giannelis, Polymer, 1997).

Several reports in the literature indicate that the enhancement in the physical properties, such as mechanical, thermal and barrier properties of the nanocomposites, are observed when the incorporation of an organoclay to a polymer matrix led to randomly dispersed, individually delaminated silicate platelets to prepare clay-based polymer nanocomposites. For example, the pioneering work of the Toyota researchers showed well-dispersed clay platelets in the nylon 6 nanocomposites that have exhibited better mechanical and thermal properties as compared with the pure nylon 6 , as well as improved stiffness without much change in the toughness (Okada and Usuki, 1995; Kawasumi, 2004; Kojima et al., 1994; Usuki et al., Interaction, 1995; Usuki et al., Synthesis, 1995). 
A clay-based polyimide film was prepared by dispersing the organoclay in $N, N$-dimethyl acetamide (DMAc), then addition of diamino diphenyl ether and pyromellitic dianhydride (PMDA) was done. The solution was stirred for 6 hours. Then, the film was cast from the homogeneous mixture and heated to $300{ }^{\circ} \mathrm{C}$ to polymerize. X-ray diffraction (XRD) and transmission electron microscopy (TEM) (Figure 6) confirmed the exfoliation of the clay layered structure. At only $2 \%$ wt clay loading, the clay-poly(imide) nanocomposite exhibited $50 \%$ reduction in water and $\mathrm{CO}_{2}$ permeability (Yano et al., 1997; Yano et al., 1993). Wang and Pinnavaia (1994) (Wang and Pinnavaia et al., 1994) reported the delamination of modified MMT clay in the preparation of an epoxy resin nanocomposite. The delamination of the clay filler into nanometerthick layers was confirmed by transmission electron micrographs. Also, the diffraction experiments revealed the absence of clay reflections in the X-ray powder diffraction patterns confirming the loss of ordering in the clay filler.

(a)

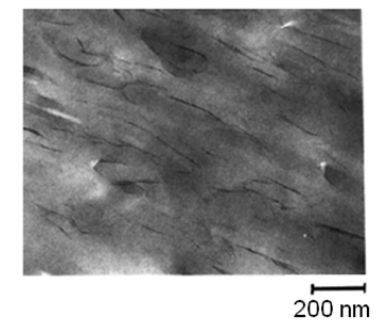

(b)

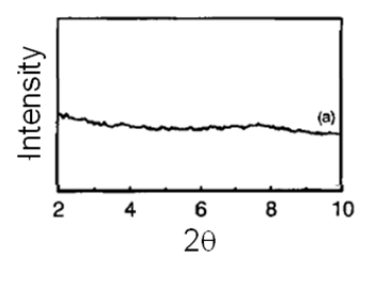

Figure 6. (a) TEM Image and (b) XRD Profile of an Exfoliated Polyimide-MMT Nanocomposite (Yano et al., Synthesis, 1997).

Chen and co-workers (1999) and Okamoto and co-researchers (2000) worked on polymerization of methyl methacrylate (MMA) in the presence of previously modified MMT clay and were successful in preparing partially exfoliated PMMA nancomposites. Giannelis (1996) achieved delamination of MMT clay to prepare an exfoliated PMMA nanocomposite that exhibited a $6{ }^{\circ} \mathrm{C}$ increase in glass transition $\left(\mathrm{T}_{\mathrm{g}}\right)$ temperature and 50 ${ }^{\circ} \mathrm{C}$ increase in the decomposition temperature.

Jin et al. (2002) reported exfoliated organo-modified MMT clay in a poly(ethylene) nanocomposite. The nanocomposite is prepared by Ziegler-Natta polymerization of ethylene in the presence of a commercially available organoclay, Cloisite30B. Cloisite30B contains methyl tallow bis(2hydroxyethyl) quaternary ammonium $\left(\mathrm{MT}_{2} \mathrm{EtOH}\right)$ between the silicate layers. Ethylene polymerization inside the clay galleries was made possible through bound catalysts found in between clay layers. Prior to polymerization, the catalyst, $\mathrm{TiCl}_{4}$, was attached to the clay surface through its reaction with the hydroxyl groups of the intercalating agent. The presence of the hydroxyl groups in the intercalation agents offers facile reactive sites for anchoring catalysts in between silicate layers.

Other authors have reported the preparation of exfoliated nanocomposites by incorporating modified clay in different polymeric materials that include poly(amides) (Kojima et al., 1994; Usuki et al., Interaction, 1995; Zhang et al., Crystal, 2006; Fornes et al., 2002), poly(olefins) (Jin et al., 2002; Zhang et al., Controlled, 2006; Alexandre et al., Polyethylene-layered, 2002), poly(styrenes) and poly(imides) (Yano et al., 1997; Yano et al., 1993).

While the exfoliated morphology is desirable for clay-based nanocomposites to achieve various significant property improvements, it is not easy to achieve complete exfoliation of clays. Several factors are found to influence the degree of delamination in clay-based polymer nanocomposites.

Based on their work on epoxy nanocomposites, Lan et al. (1995) found the type of surfactants used to pre-treat the MMT filler influences the morphology of the nanocomposite. An exfoliated epoxy nanocomposite was obtained when the clay filler was previously modified with primary and secondary onium salts. The use of tertiary and quaternary surfactants to surface modify the clay resulted to intercalation.

\section{NANOCOMPOSITE PREPARATION}

The remarkable improvements in the physical properties of polymeric materials due to the incorporation of clay fillers have led to the increased attention on the preparation of clay-based polymer nanocomposites in recent years. These significant enhancements have been attributed to the nanometer dimensions of the clay fillers (Alexandre and Dubois, Polymer-layered, 2000; Vaia and Giannelis, Lattice, 1997; Decker et al., 2005; Ramesh and Punithamurthy, 20017; Venugopal et al., 2016; Majka et al., 2016; Li, 2016; Khandal et al., 2016; Triantou et al., 2015; Mattausch, 2015; Hoang et al., 2015; Giroto et al., 2015). The most significant enhancements have been observed in the nanocomposites where a complete delamination of the clay structure (exfoliation) is achieved. The clay particles may also be dispersed in aggregates that retain their layered structure (intercalated state) with polymer chains embedded between the clay sheets requiring the layers farther apart. The hydrophilic clay particles are typically modified prior to their use in nanocomposite preparation. 
Even with the incorporation of organomodified clays, the complete exfoliation of clay particles is usually difficult to attain. Different techniques of nanocomposite preparation have been utilized to facilitate exfoliation of the clay fillers to varying degrees of success. There are three principal strategies to prepare polymer-clay nanocomposites including solution-blending (Horsch et al., 2006; Hasegawa et al., 2003), melt intercalation (Giannelis, 1996; Vaia et al., New, 1995; Fornes et al., 2002; Cho and Paul, 2001; Vaia et al., Synthesis, 1993; Colonna et al., 2010; Sinha Ray et al., Structure-property, 2003) and in situ intercalative polymerization (Huang and Brittain, 2001; Weimer et al., 1999; Okamoto et al., 2000) (Figure 7).

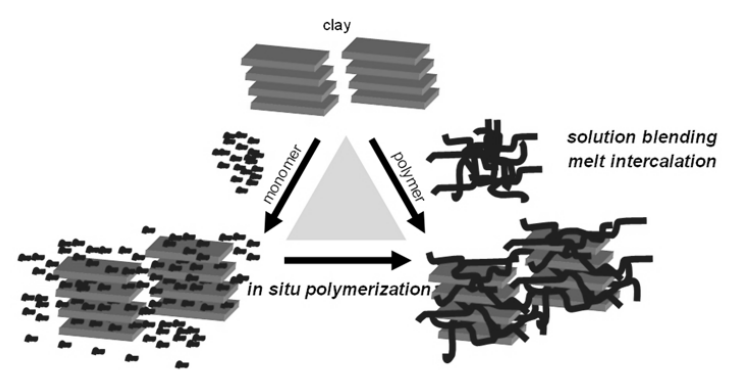

Figure 7. Three Common Methods of Preparation of a Clay-based Polymer Nanocomposite: Solution Blending, Melt Intercalation and in situ Intercalative Polymerization.

Solution Blending. Solution blending involves mixing a pre-formed polymer solution with clay. In this method, the polymer is solubilized in an appropriate solvent and then the clay is dispersed. The selected solvent should dissolve both the polymer and the clay filler. The selection of a proper solvent is a key factor to achieve a high degree of exfoliation of the clay structure in the polymer ( $\mathrm{Li} e t$ al., 2016; Ho and Glinka, 2003; Shori et al., 2015; Ziadeh, 2014). In the case of the clay, the solvent needs to promote swelling in the layered structure so that the polymer chains can intercalate between the galleries. When the solutions of the pre-formed polymer and the layered silicate clays are mixed, the polymer chains intercalate in the interlayers of the layered silicates. Subsequently, the solvent is evaporated or the polymer is precipitated to recover the nanocomposites. This method of nanocomposite preparation is widely used involving water-soluble polymers because of the need for large amounts of the solvent to ensure a good dispersion of clay. The intercalation of polymers in the clay galleries can also be possible in the presence of organic solvent. For instance, poly(ethylene oxide) (PEO) has been successfully intercalated in sodium clay and sodium hectorite by dispersion in acetonitrile (Wu and Lerner, 1993).
The solution blending method was first utilized by Aranda and Ruiz-Hitzky in 1992 to prepare a PEO/ MMT nanocomposite. Different polar solvents (e.g. water, methanol and 1:1 mixtures of these solvents) were used to swell the MMT clay in order to intercalate the PEO chains. They observed that the high polarity of water promotes cracking of the PEO films while methanol was not suitable for the high molecular weight PEO. However, 1:1 mixture of water and methanol appeared to be useful for the intercalation of the PEO inside the MMT galleries although cracking of the PEO films was still observed.

Most often, the clay is usually modified to become compatible with the polymer matrix. For example, in the work of Jeon et al. (1998) involving nanocomposites prepared from nitrile-based copolymers and poly(ethylene)-based polymers using sodium montmorillonite $\left(\mathrm{Na}^{+}-\mathrm{MMT}\right)$ that was organically modified by treatment with protonated dodecylamine prior to solution blending. Greater dispersion was found in the nitrile-based copolymer rather than in the poly(ethylene)-based, suggesting differences in the degree of physical interaction with the modified clay. Instead of being individually dispersed, most layers were found in thin stacks comprising several swollen layers.

Pramanik and co-workers (2003) reported the preparation of an ethylene vinyl acetate (EVA)clay nanocomposite. A copolymer of ethylene and vinyl acetate was solution blended with an organomodified MMT clay to prepare EVA-clay nanocomposite. The copolymer contains $12 \%$ vinyl acetate and is solubilized in toluene. The MMT clay is modified by intercalating with a dodecyl ammonium ion before dispersion in N,N-dimethyl acetamide (DMAc). The solution blending of the organoclay in the copolymer resulted in clay-polymer nanocomposites with delaminated configuration up to $6 \%$ wt of the clay fillers. At $8 \%$ wt clay loading, the hybrid registered a d001 peak at about $2 \theta=5.6$, an indication of aggregation of the aluminosilicate layers in the matrix. The significant enhancement in the properties of the nanocomposites with exfoliated morphology were observed. For instance, the nanocomposite filled with $2 \%$ wt clay exhibited a tensile strength that is $36 \%$ higher as compared with the neat ethylene vinyl acetate copolymer.

Melt Intercalation. Melt intercalation is a method involving mixing of the layered silicate with the polymer matrix in the molten state (Vaia and Giannelis, Lattice, 1997; Vaia et al., Synthesis, 1993; Vaia and Giannelis, Polymer, 1997; Cui et al., 2015; Crétois et al., 2015; Vuluga et al., 2014; Souza, 2013). The blending process involves the mixing 
of the silicate clay fillers with polymer pellets at a temperature above the softening point of the polymer matrix (Giannelis, 1996). During the process, the polymer chains diffuse from the bulk polymer melt into the interlayers between the silicate platelets. A range of nanocomposites with varying degree of intercalation/exfoliation can be obtained depending on the degree of penetration of the polymer chains into the silicate galleries. In 1993, Giannelis and co-worker (1993) were the first to show that it is possible to melt-mix polymers with clays without the use of organic solvents. Compared to solution dispersion and in situ intercalative polymerization techniques, an advantage of melt intercalation as a method of nanocomposite preparation is that no solvent is required. The direct intercalation of the polymer chains inside the host clay galleries was made possible by mixing the clay with a polymer powder and then pressing the mixture into a pellet and heating the polymer-clay mixture at an appropriate temperature. For example, in the case of poly(styrene) (PS), the polymer ( $\mathrm{Mw}=400,000$ $\mathrm{g} /$ mole) was intercalated by mixing $0.25 \mathrm{~g}$ of PS with $0.75 \mathrm{~g}$ of alkyl ammonium MMT into a pellet and heating the pellet in vacuum at $165^{\circ} \mathrm{C}$. This temperature is well above the bulk glass transition temperature of PS $\left(96^{\circ} \mathrm{C}\right)$ ensuring the presence of a polymer melt.

Aside from the elimination of the use of solvent, this approach is appealing to industry as it can be combined with existing conventional polymer processing techniques like extrusion that would greatly expand the commercial opportunities for this technology. Melt compounding is more economical and simple since this process eliminates the use of solvent and would allow direct preparation of nanocomposites using ordinary compounding devices such as extruders or other mixers. These attributes of a melt intercalation make it a viable method to prepare nanocomposites from polymers that are produced on large scales industrially. Melt intercalation is broadly applicable to many commodity and engineering polymers ranging from non-polar poly(olefins) to strongly polar poly(amides) (Tjong, 2006).

One important consideration in the use of this solvent-free method as a method of preparing polymer nanocomposites is the compatibility requirement between the polymer and the clay layer surfaces. In addressing the compatibility issue between the inorganic clay and the organic matrix, a silicate clay is usually derivatized first with alkyl ammonium cations via an ion exchange reaction prior to mixing. The direct polymer melt intercalation can be used to prepare nanocomposites where polymer chains can diffuse into the space between the clay layers or galleries. The outcome of polymer intercalation in the galleries of the host silicate clay depends critically on the compatibility between the clay fillers and the polymer bulk. Sinha Ray and Okamoto (2003) pointed out that the most favorable inorganic host for nanocomposite formation using this process is a modified clay that has an optimal interlayer structure (e.g. the alkyl chains of the modifiers are long enough and the number of chains per area is sufficient to permit intercalation). The polymer intercalation depends on the existence of a favorable interaction between the modified clay and the polymer matrix. By prudent choice of the alkyl ammonium cation, the interactions between the host layer and the intercalated polymer can be used to prepare polymer-clay nanocomposites.

Using numerical self-consistent field (SCF) calculations, Balazs et al. (1998) and Zhulina et al. (1999) investigated the factors that affect the intercalation of polymer molecules during melt into the layered structure of the clay host. They found that having the surfactants previously used to modify the host clay to be of the same length as intercalating polymer chains favors greater separation of the clay layers as this allows the polymers to access more conformational degrees of freedom. They further reported that the density of the surfactant can affect the penetration of the polymer chains during melt intercalation, indicating that a high surfactant density can prevent the intercalation of chains further inside the clay host galleries. Thus, it is important in the preparation of a clay-based polymer nanocomposite to select the appropriate organoclay.

Cho and Paul (2001) used a conventional screw extruder to prepare a clay-polyamide nanocomposite by melt compounding. The exfoliation of the organo-modified MMT clay in the nylon 6 matrix was achieved using a twin screw extruder but the use of a single screw extruder was far less effective. The mechanical properties like the tensile modulus and yield strength of these organoclay nanocomposites were significantly increased with a marginal decrease of ductility compared to the unfilled nylon 6 . Also, the mechanical property measurements of the clay-based nanocomposites yielded much greater values than their glass fiber composite counterparts prepared using the same process.

A clay-based nylon nanocomposite was prepared by Liu et al. (1999) using a melt intercalation process. The MMT clay was first modified using an ion exchange reaction with an octadecyl ammonium salt prior to the melt compounding with nylon 6 in a twin-screw extruder. The mechanical and thermal properties of the nanocomposite are superior to those of the the bare nylon 6 in terms of the heat 
distortion temperature, strength and modulus. At a $4.2 \%$ weight clay reinforcement, the nanocomposite has a higher heat distortion temperature, $112{ }^{\circ} \mathrm{C}$ compared to the neat nylon 6 which distorts at 62 ${ }^{\circ} \mathrm{C}$. Similarly, mechanical properties that include yield strength, flexural strength, and modulus all have been improved while not sacrificing its impact strength.

In situ Intercalative Polymerization. In the in situ intercalative polymerization, the monomer together with the initiator and/or catalyst is mixed with the silicate layers and is intercalated within the interlayers of the host silicates. The polymerization is then initiated using external stimulation such as thermal, photochemical or chemical activation (Akat et al., 2008; Nese et al., 2006; Yenice et al., 2009). With the monomers and the initiators and/or catalysts found in the interlayers, the polymerization occurs inside the clay galleries of the host silicates. As the polymer chains grow inside the host clay galleries, the clay sheets are gradually exfoliated. The growing polymer chains in the clay galleries make the platelets far apart until the inorganic phase loses its registry of an ordered arrangement leading to the delamination of the silicate filler in the polymer matrix. Since the polymer growth inside the galleries serves as the driving force for the exfoliation of the host layered structure, the success of the clay delamination would depend on how much initiators and/or catalysts diffuse into the interlayers of the host clay.

This approach was first utilized by the Toyota researchers using a layered clay as a filler to a polyamide matrix in the 1980 s to prepare polymerclay nanocomposites that they referred to as nylonclay hybrids (NCH) (Kawasumi, 2004; Kojima et al., 1994, Usuki et al., Interaction, 1995; Usuki et al., Synthesis, 1995; Yano et al., 1997; Yano et al., 1993; Hasegawa et al., 2000). They were able to swell a montmorillonite clay derivative that was previously modified with an amino acid modifier by the addition of caprolactam. The intercalated monomer was then subsequently polymerized in the interlayer of the montmorillonite clay yield a nylon 6-clay hybrid (NCH).

They organically modified sodium montmorillonite $\left(\mathrm{Na}^{+}-\mathrm{MMT}\right)$ clay with various protonated aminoacids. The carboxyl group of the anchored amino acid modifier initiated the ring-opening polymerization of the $\varepsilon$-caprolactam monomer. They observed that the swelling behavior of the modified clays depends on the chain length of the amino acid modifier with the longer modifier facilitating the insertion of larger amount of the monomers inside the galleries of the host MMT clay.
The polymerization of the caprolactam is initiated from the carboxylic acid groups of the alkyl ammonium cations ionically tethered to the MMT clay. The growing polymer chains forced the silicate layers far apart. Morphological studies of the $\mathrm{NCH}$ showed that the silicate layers of the clay fillers were uniformly dispersed in the nylon 6 matrix.

In an in situ polymerization, the polymer chains are tethered to the surface of the silicate filler through an ionic interaction between the negatively charged silicate surface and the positively charged ammonium cation located at one end of the polymer chain (Advincula, 2006; Zhou et al., 2001).

Messersmith and Giannelis (1995) utilized the same approach observed by the Toyota researchers in preparing biodegradable aliphatic polyester nanocomposites. The nanocomposites consist of homogeneously dispersed two-dimensional layers of an organically modified silicate (OMS) clay within the poly(e-caprolactone) matrix. They reported that the homogeneous dispersion of the clay fillers in the nanocomposites significantly improved the barrier properties of the nanocomposite films as compared to the unfilled poly( $\varepsilon$-caprolactone).

To prepare the OMS clay, an ion exchange reaction between $\mathrm{Na}^{+}$-MMT clay and 12-aminododecanoic acid was performed. A number of $\operatorname{poly}(\varepsilon-$ caprolactone)-silicate nanocomposites (PCLC) were synthesized by mixing different amounts of the OMS (0-30\% by weight) with the $\varepsilon$-caprolactone monomer in a vial at room temperature for 1 to 2 $\mathrm{h}$ followed by heating in an oil bath with stirring at $17 \mathrm{O}^{\circ} \mathrm{C}$ for $48 \mathrm{~h}$. During this process, the $-\mathrm{COOH}$ groups of the ionically tethered modifier of the host silicate initiate the ring-opening polymerization of the heterocyclic $\varepsilon$-caprolactone monomer. The product is a polymer-clay nanocomposite with the polyester chains directly grown from the silicate clay surfaces.

Aside from the ring-opening polymerization, other techniques have been used to prepare various polymer-clay nanocomposites via in situ intercalative polymerization method such as conventional free radical polymerization, controlled radical polymerization, and anionic and cationic polymerization (Lee and Jang, Preparation, 1996; Forte et al., 1998; Biasci et al., 1994; Al-Esaimi, 1997; Tseng et al., 2002; Moet and Akelah, 1993; Doh and Cho, 1998).

Using free radical polymerization technique, the successful intercalation of polymers in the host silicate clay has been achieved through the addition to the clay suspension of a solution of vinyl monomer such 
as methyl methacrylate (Lee and Jang, 1996; Forte et al., 1998; Biasci et al., 1994; Al-Esaimi, 1997), and styrene (Fu and Qutubuddin, 2001; Tseng et al., 2002; Moet and Akelah, 1993; Akelah et al., 1994; Doh and Cho, 1998). For example, Okamoto et al. (2000) prepared a clay-poly(methyl methacrylate) (PMMA) nanocomposite via an in situ intercalative free radical polymerization using smectic clays that are initially modified with an alkyl ammonium salt. t-butyl peroxy-2-ethylhexanate was used as an initiator and was mixed in the suspensions $(0.1 \mathrm{wt} \%)$. The free radical polymerization of the monomer was carried out in the dark at $80^{\circ} \mathrm{C}$ for 5 hours. While only intercalation of the filler was achieved and not exfoliation, the nanocomposite exhibited higher storage modulus and higher glass transition temperature compared to the neat polymer. The preparation of other PMMA-clay nanocomposites prepared by in situ free radical polymerization were reported by Biasci et al. (1994), Lee and Jang (1996); and Forte et al. (1998).

Utilizing in situ free radical polymerization, several clay-poly(styrene) (PS) nanocomposites were also successfully prepared with the PS chains intercalated between the host clay galleries. This was achieved by initially intercalating the styrene monomers in the galleries of the host MMT clay followed by subsequent free radical polymerization of the styrenes as reported by Akeelah and Moet (1981), Meier et al. (1994), Doh and Cho (1998), and $\mathrm{Fu}$ and Qutubuddin (2001). To ensure the in situ polymerization of the styrenes inside the clay galleries, the host clay is previously modified to ionically anchor the radical initiator, in the process, yielding a PS film that is directly attached to the clay surfaces and intercalated between the silicate platelets.

\section{INSIGHTS AND PERSPECTIVES}

In a clay-based polymer nanocomposite, the homogeneous dispersion of delaminated clay fillers in the polymer matrix provides a means of creating hybrid materials that integrate the desirable features of the filler and the bulk material. Also, the synergy between the filler particles and the polymer matrix that are on similar nanometer scales and the large quantity of interfacial area relative to the volume of the material led to significant improvements in the properties of the nanocomposites. A key to these two important concepts is the chemical modification of the clay filler. The advances gained in controlled living polymerization methodologies can be utilized to modify clay. The concept behind this approach is to promote clay exfoliation by facilitating the intercalative polymerization of monomers to occur in the galleries of the layered structure of silicate clays. The direct attachment of polymer chains onto clay particles have the obvious advantage of producing organic-inorganic hybrid materials that are more thermodynamically stable as compared with clay composites prepared by physically blending a clay filler and a polymer matrix. In this type of nanocomposites, there is a strong interfacial effect between the layered silicate fillers and matrix polymers.

\section{CONCLUSION}

Over the last forty years, two important research outputs have contributed immensely in the increased attention in the field of polymer nanocomposites. In the 1980s, the first silicate-based nanocomposite was prepared from a polyamide by scientists from the Toyota's Central Research and Development Laboratories (CRDL). The researchers were able to synthesize nylon-clay hybrid (NCHs) using in situ intercalative polymerization technique. The $\mathrm{NCHs}$ have exhibited substantial increases in the tensile strength, modulus and heat distortion temperature. While higher modulus and tensile strength were noted for the $\mathrm{NCHs}$, interestingly, the impact strength of the hybrid did not suffer any reduction as usually expected in conventional composite materials. These remarkable property enhancements led to the first commercial application of clay-filled polymer in the manufacture of timing belt cover on Toyota cars. Then in 1993, the research team of Vaia $e t$ al. showed that it is possible to prepare a clay-based polymer nanocomposite by melt mixing polymers with clays previously modified with cationic organic surfactants. This process eliminates the use of organic solvents. This is very appealing from the point of view of the industries as clay-based polymer-nanocomposites can be prepared using existing industrial setups. The elimination of the use of large amount of solvents also reduces production cost. These approaches of preparing polymer-clay nanocomposites have opened the doors for vigorous research works aimed at enhancing properties of various types of polymers in recent years.

\section{ACKNOWLEDGMENT}

The author would like to acknowledge the helpful discussion and insights of Prof. Thomas AP Seery of the University of Connecticut.

\section{REFERENCES}

Advincula R. Polymer Brushes by Anionic and Cationic Surface-Initiated Polymerization (SIP). In: Surface-Initiated Polymerization I. Berlin/ Heidelberg: Springer-Verlag; p. 107-36. 
Akat H, Tasdelen MA, Prez F Du, Yagci Y. Synthesis and characterization of polymer/clay nanocomposites by intercalated chain transfer agent. Eur Polym J. 2008 Jul;44(7):1949-54.

Akelah A, Rehab A, Selim A, Agag T. Synthesis and application of organophilic polystyrenemontmorillonite supported onium salts in organic reactions. J Mol Catal. 1994 Dec;94(3):311-22.

Al-Esaimi MM. Reaction catalyzed by montmorillonite: Polymerization of methyl methacrylate. J Appl Polym Sci. 1997 Apr $11 ; 64(2): 367-72$.

Alexandre M. Polyethylene-layered silicate nanocomposites prepared by the polymerizationfilling technique: synthesis and mechanical properties. Polymer. 2002;43(8):2123-32.

Alexandre M, Beyer G, Henrist C, Cloots R, Rulmont A, Jérôme R, et al. "One-Pot" Preparation of Polymer/Clay Nanocomposites Starting from $\mathrm{Na}+$ Montmorillonite. 1. Melt Intercalation of Ethylene-Vinyl Acetate Copolymer. Chem Mater. 2001 Nov;13(11):3830-2.

Alexandre M, Dubois P. Polymer-layered silicate nanocomposites: preparation, properties and uses of a new class of materials. Mater Sci Eng R Reports. 2000 Jun;28(1-2):1-63.

Aranda P, Ruiz-Hitzky E. Poly(ethylene oxide)silicate intercalation materials. Chem Mater. 1992 Nov;4(6):1395-403.

Balazs AC, Singh C, Zhulina E. Modeling the Interactions between Polymers and Clay Surfaces through Self-Consistent Field Theory. Macromolecules. 1998 Nov;31(23):8370-81.

Bergaya F, Detellier C, Lambert J-F, Lagaly G. Introduction to Clay-Polymer Nanocomposites (CPN). In 2013. p. 655-77.

Biasci L, Aglietto M, Ruggeri G, Ciardelli F. Functionalization of montmorillonite by methyl methacrylate polymers containing sidechain ammonium cations. Polymer. 1994 Jul;35(15):3296-304.

Bledzki A. Composites reinforced with cellulose based fibres. Prog Polym Sci. 1999 May;24(2):22174.

Chen G, Chen X, Lin Z, Ye W, Yao K. Preparation and properties of PMMA/clay nanocomposite. J Mater Sci Lett. 1999;18(21):1761-3.
Chen K, Guo B, Luo J. Quaternized carboxymethyl chitosan/organic montmorillonite nanocomposite as a novel cosmetic ingredient against skin aging. Carbohydr Polym. 2017 Oct;173:100-6.

Cho J., Paul D. Nylon 6 nanocomposites by melt compounding. Polymer. 2001 Feb;42(3):1083-94.

Colonna M, Berti C, Binassi E, Fiorini M, Karanam $S$, Brunelle DJ. Nanocomposite of montmorillonite with telechelic sulfonated poly(butylene terephthalate): Effect of ionic groups on clay dispersion, mechanical and thermal properties. Eur Polym J. 2010 May;46(5):918-27.

CrétoisR, Follain N, Dargent E, SoulestinJ, Bourbigot S, Marais S, et al. Poly(3-hydroxybutyrate-co-4hydroxybutyrate) based nanocomposites: influence of the microstructure on the barrier properties. Phys Chem Chem Phys. 2015;17(17):11313-23.

Cui Y, Kumar S, Rao Kona B, van Houcke D. Gas barrier properties of polymer/clay nanocomposites. RSC Adv. 2015;5(78):63669-90.

Decker C, Keller L, Zahouily K, Benfarhi S. Synthesis of nanocomposite polymers by UV-radiation curing. Polymer. 2005 Aug;46(17):6640-8.

Doh JG, Cho I. Synthesis and properties of polystyrene-organoammonium montmorillonite hybrid. Polym Bull. 1998 Nov 16;41(5):511-8.

Eichhorn SJ, Baillie CA, Zafeiropoulos N, Mwaikambo LY, Ansell MP, Dufresne A, et al. Review: Current international research into cellulosic fibres and composites. J Mater Sci. 2001 May;36(9):2107-31.

Fischer HR, Gielgens LH, Koster TPM. Nanocomposites from polymers and layered minerals. Acta Polym. 1999 Apr 1;50(4):122-6.

Fornes T., Yoon P., Hunter D., Keskkula H, Paul D. Effect of organoclay structure on nylon 6 nanocomposite morphology and properties. Polymer. 2002 Jan;43(22):5915-33.

Forte C, Geppi M, Giamberini S, Ruggeri G, Veracini CA, Mendez B. Structure determination of clay/methyl methacrylate copolymer interlayer complexes by means of $13 \mathrm{C}$ solid state n.m.r. Polymer. 1998;39(12):2651-6.

Fu X, Qutubuddin S. Polymer-clay nanocomposites: exfoliation of organophilic montmorillonite nanolayers in polystyrene. Polymer. 2001 Jan;42(2):807-13. 
Giannelis EP. Polymer Layered Silicate Nanocomposites. Adv Mater. 1996 Jan;8(1):29-35.

Giroto AS, de Campos A, Pereira EI, Ribeiro TS, Marconcini JM, Ribeiro C. Photoprotective effect of starch/montmorillonite composites on ultravioletinduced degradation of herbicides. React Funct Polym. 2015 Aug;93:156-62.

Goldstein AN, editor. Handbook of nanophase materials. Vol. 32, Materials Research Bulletin. New York: Marcel Dekker, Inc.; 1997. 1723 p.

Hajibeygi M, Shabanian M, Khodaei-Tehrani M. New heat resistant nanocomposites reinforced silicate nanolayers containing triazine rings based on polyamide: Synthesis, characterization, and flame retardancy study. Polym Compos. 2016 Jan;37(1):188-98.

Hasegawa N, Okamoto $\mathrm{H}$, Kato M, Usuki A, Sato N. Nylon 6/Na-montmorillonite nanocomposites prepared by compounding Nylon 6 with $\mathrm{Na}$-montmorillonite slurry. Polymer. 2003 May;44(10):2933-7.

Hasegawa N, Okamoto H, Kawasumi M, Kato M, Tsukigase A, Usuki A. Polyolefin-clay hybrids based on modified polyolefins and organophilic clay. Macromol Mater Eng. 2000 Aug 1;280-281(1):769 .

Hedenberg P, Gatenholm P. Conversion of plastic/cellulose waste into composites. I. Model of the interphase. J Appl Polym Sci. 1995 May 9;56(6):641-51.

Ho DL, Glinka CJ. Effects of solvent solubility parameters on organoclay dispersions. Chem Mater. 2003;15(6):1309-12.

Hoang T, Wei C, Yang Y. Tribological Study on Clay and CNF Epoxy Glass Fiber Composited Materials. In: Proceedings of the 14th IFToMM World Congress. 2015. p. 521-6.

Hong SI, Rhim JW. Preparation and properties of melt-intercalated linear low density polyethylene/ clay nanocomposite films prepared by blow extrusion. LWT - Food Sci Technol. 2012;48(1):43-51.

Horsch S, Serhatkulu G, Gulari E, Kannan RM. Supercritical CO2 dispersion of nano-clays and clay/polymer nanocomposites. Polymer. 2006;47(21):7485-96.

Huang X, Brittain WJ. Synthesis and characterization of PMMA nanocomposites by suspension and emulsion polymerization. Macromolecules. 2001;34(10):3255-60.

Jeon HG, Jung H-T, Lee SW, Hudson SD. Morphology of polymer/silicate nanocomposites High density polyethylene and a nitrile copolymer. Polym Bull. 1998;41(1):107-13.

Jin Y-H, Park H-J, Im S-S, Kwak S-Y, Kwak S. Polyethylene/Clay Nanocomposite by In-Situ Exfoliation of Montmorillonite During ZieglerNatta Polymerization of Ethylene. Macromol Rapid Commun. 2002 Jan 1;23(2):135-40.

Kawasumi M. The discovery of polymer-clay hybrids. J Polym Sci Part A Polym Chem. 2004;42(4):819_ 24.

Khandal D, Pollet E, Avérous L. Elaboration and behavior of poly(3-hydroxybutyrate-co-4hydroxybutyrate)- nano-biocomposites based on montmorillonite or sepiolite nanoclays. Eur Polym J. 2016;81:64-76.

Kim S, Palomino AM. Factors influencing the synthesis of tunable clay-polymer nanocomposites using bentonite and polyacrylamide. Appl Clay Sci. 2011;51(4):491-8.

Kojima Y, Usuki A, Kawasumi M, Okada A, Kurauchi T, Kamigaito O, et al. Fine-Structure of Nylon-6-Clay Hybrid. J Polym Sci Part B-Polymer Phys. 1994;32(4):625-30.

Kornmann X, Lindberg H, Berglund L a. Synthesis of epoxy - clay nanocomposites : influence of the nature of the clay on structure. Polymer. 2001;42(4):1303-10.

Lambert JF, Bergaya F. Smectite-polymer nanocomposites. Dev Clay Sci. 2013;5:679-706.

Lan T, Kaviratna PD, Pinnavaia TJ. Mechanism of Clay Tactoid Exfoliation in Epoxy-Clay Nanocomposites. Chem Mater. 1995;7(11):214450.

Lee DC, Jang LW. Characterization of epoxy-clay hybrid composite prepared by emulsion polymerization. J Appl Polym Sci. 1998;68(12):1997-2005.

Lee DC, Jang LW. Preparation and Characterization of PMMA-Clay Hybrid Composite by Emulsion Polymerization. J Appl Polym Sci. 1996;61:111722.

Li H, Ren W, Zhu J, Xu S, Wang J. Rheology and 
Processing of Laponite/Polymer Nanocomposites. In: Rheology and Processing of Polymer Nanocomposites. Hoboken, NJ, USA: John Wiley \& Sons, Inc.; 2016. p. 383-404.

Liu L, Qi Z, Zhu X. Studies on nylon 6/clay nanocomposites by melt-intercalation process. J Appl Polym Sci. 1999;71(7):1133-8.

Majka TM, Leszczyńska A, Pielichowski K. Thermal stability and degradation of polymer nanocomposites. Polym Nanocomposites Electr Therm Prop. 2016;167-90.

Marchante V, Beltrán M. Montmorillonite Polyethylene Nanocomposites. Polyethyl Based Blends, Compos Nanocomposities. 2015;257-80.

Marques MDF V, Fernandes RM. Influence of Polypropylene Reaction Time on the Clay Exfoliation Process by In Situ Polymerization. J Nanosci Nanotechnol. 2017 Jul 1;17(7):5095-103.

Martino L, Guigo N, van Berkel JG, Sbirrazzuoli N. Influence of organically modified montmorillonite and sepiolite clays on the physical properties of bio-based poly(ethylene 2,5-furandicarboxylate). Compos Part B Eng. 2017;110:96-105.

Mattausch H. Properties and applications of nanoclay composites. Polym Nanoclay Compos. 2015;127-55.

Meier LP, Shelden RA, Caseri WR, Suter ' UW. Polymerization of Styrene with Initiator Ionically Bound to High Surface Area Mica: Grafting via an Unexpected Mechanism. Macromolecules. 1994;27:1637-42.

Messersmith PB, Giannelis EP. Synthesis and Barrier Properties of Poly(e-Caprolactone)-Layered Silicate Nanocomposites. J Polym Sci A Polym Chem. 1995;33:1047-57.

Moet AS, Akelah A. Polymer-clay nanocomposites: polystyrene grafted onto montmorillonite interlayers. Mater Lett. 1993;18(1-2):97-102.

Moustafa H, Duquesne S, Haidar B, Vallat MF. Influence of the degree of exfoliation of an organoclay on the flame-retardant properties of cross-linked ethylene-co-Propylene-co-diene monomer-g-Maleic anhydride-based composites. Polym Compos. 2017;38(5):966-73.

Nese A, Sen S, Tasdelen MA, Nugay N, Yagci Y. Clay-PMMA nanocomposites by photoinitiated radical polymerization using intercalated phenacyl pyridinium salt initiators. Macromol Chem Phys. 2006;207(9):820-6.

Noh MW, Lee DC. Synthesis and characterization of PS-clay nanocomposite by emulsion polymerization. Polym Bull. 1999;42(5):619-26.

O. K. Synthesis of nylon 6-clay hybrid. J Mater Res. 1993;8(5):1179.

Ogasa T, Takahashi J, Kemmochi K. Polymer-based composite materials in general industrial fields. Adv Compos Mater. 1995;4(3):221-35.

Ogawa M, Kuroda K. Preparation of InorganicOrganic Nanocomposites through Intercalation of Organoammonium Ions into Layered Silicates. Bull Chem Soc Jpn. 1997;70(11):2593-618.

Okada A, Usuki A. Twenty Years of Polymer-Clay Nanocomposites. Macromol Mater Eng. 2006 Dec 8;291(12):1449-76.

Okada A, Usuki A. The chemistry of polymer-clay hybrids. Mater Sci Eng C. 1995;3(2):109-15.

Okada A, Usuki A. Twenty years of polymerclay nanocomposites. Macromol Mater Eng. 2006;291(12):1449-76.

Okamoto M, Morita S, Kim YH, Kotaka T, Tateyama H. Synthesis and structure of smectic clay/poly(methyl methacrylate) and clay/ polystyrene nanocomposites via in situ intercalative polymerization. Polymer. 2000;41(10):3887-90.

Osman AF, Tuty TF, Rakibuddin M, Hashim F, Tuan Johari SAT, Ananthakrishnan R, et al. Pre-dispersed organo-montmorillonite (organo-MMT) nanofiller: Morphology, cytocompatibility and impact on flexibility, toughness and biostability of biomedical ethyl vinyl acetate (EVA) copolymer. Mater Sci Eng C. 2017;74:194-206.

Penaloza DP, Sandberg DJ, Giotto MV, Seery TAP. An exfoliated clay-poly(norbornene) nanocomposite prepared by metal-mediated surface-initiated polymerization. Polym Eng Sci. 2015;55(10).

Pramanik M, Srivastava SK, Samantaray BK, Bhowmick a. K. EVA/clay nanocomposite by solution blending: Effect of aluminosilicate layers on mechanical and thermal properties. Macromol Res. 2003;11(4):260-6.

Ramesh S, Punithamurthy K. The effect of organoclay on thermal and mechanical behaviours of thermoplastic polyurethane nanocomposites. Dig 
J Nanomater Biostructures. 2017;12(2):331-8.

Ray SS, Okamoto K, Okamoto M. Structureproperty relationship in biodegradable poly(butylene succinate)/layered silicate nanocomposites. Macromolecules. 2003;36(7):2355-67.

Rong MZ, Zhang MQ, Liu Y, Yang GC, Zeng HM. The effect of fiber treatment on the mechanical properties of unidirectional sisal-reinforced epoxy composites. Compos Sci Technol. 2001 Aug;61(10):1437-47.

Schauberger JG, Riess G, Kern W. Preparation of UV reactive montmorillonite and characterization of its nanocomposites with poly(vinyl alcohol). J Appl Polym Sci. 2013;130(1):665-72.

Shakoor A, Rizvi TZ, Hina M. Charge transport mechanism in intercalated polypyrrole aluminumpillared montmorillonite clay nanocomposites. J Appl Polym Sci. 2012;124(4):3434-9.

Shori S, Chen X, Peralta M, Gao H, Zur Loye HC, Ploehn HJ. Effect of interfacial pretreatment on the properties of montmorillonite/poly(vinyl alcohol) nanocomposites. J Appl Polym Sci. 2015;132(18).

Sinha Ray S, Okamoto M. Polymer/layered silicate nanocomposites: A review from preparation to processing. Prog Polym Sci. 2003;28(11):1539-641.

Song EH, Kang BH, Kim TY, Lee HJ, Park YW, Kim YC, et al. Highly oriented gold/nanoclay-polymer nanocomposites for flexible gas barrier films. ACS Appl Mater Interfaces. 2015;7(8):4778-83.

Souza PMS, Corroqué NA, Morales AR, MarinMorales MA, Mei LHI. PLA and Organoclays Nanocomposites: Degradation Process and Evaluation of ecotoxicity Using Allium cepa as Test Organism. J Polym Environ. 2013;21(4):1052-63.

Spoljaric S, Salminen A, Dang Luong N, Lahtinen P, Vartiainen J, Tammelin T, et al. Nanofibrillated cellulose, poly(vinyl alcohol), montmorillonite clay hybrid nanocomposites with superior barrier and thermomechanical properties. Polym Compos. 2014;35(6):1117-31.

Strawhecker KE, Manias E. Structure and Properties of Poly(vinyl alcohol)/Na+ Montmorillonite Nanocomposites. Chem Mater. 2000;12:2943-9.

Swaminathan G, Shivakumar K. Thermomechanical and fracture properties of exfoliated nanoclay nanocomposites. J Reinf Plast Compos. 2011;30(3):256-68.
Szymczyk A, Paszkiewicz S, Roslaniec Z. Influence of intercalated organoclay on the phase structure and physical properties of PTT-PTMO block copolymers. Polym Bull. 2013;70(5):1575-90.

Tjong SC. Structural and mechanical properties of polymer nanocomposites. 2006 Aug;53:73-197.

Triantou MI, Tarantili PA, Andreopoulos AG. Melt processing and property testing of a model system of plastics contained in waste from electrical and electronic equipment. Waste Manag Res. 2015;33(5):453-9.

Tseng CR, Wu JY, Lee HY, Chang FC. Preparation and characterization of polystyrene-clay nanocomposites by free-radical polymerization. J Appl Polym Sci. 2002;85(7):1370-7.

Unuabonah EI, Taubert A. Clay-polymer nanocomposites $(\mathrm{CPNs})$ : Adsorbents of the future for water treatment. Appl Clay Sci. 2014;99:83-92.

Usuki A, Koiwai A, Kojima Y, Kawasumi M, Okada A, Kurauchi T, et al. Interaction of Nylon-6 Clay Surface and Mechanical-Properties of Nylon-6 Clay Hybrid. J Appl Polym Sci. 1995;55(1):119-23.

Usuki A, Hasegawa N, Kato M. Polymer-Clay Nanocomposites. Adv Polym Sci. 2005;179:13595.

Usuki A, Kawasumi M, Kojima Y, Okada A, Kurauchi T. Synthesis and Properties of DiamineModified Nylon 6-Clay Hybrid. Kobunshi Ronbunshu. 1995;52(7):440-4.

Usuki A, Kawasumi M, Kojima Y, Okada A, Kurauchi T, Kamigaito O. Swelling behavior of montmorillonite cation exchanged for $\omega$-amino acids by $\varepsilon$-caprolactam. J Mater Res. 1993;8(5):1174-8.

Vaia RA, Vasudevan S, Krawiec W, Scanlon LG, Giannelis EP. New polymer electrolyte nanocomposites: Melt intercalation of poly(ethylene oxide) in mica-type silicates. Adv Mater. 1995;7(2):154-6.

Vaia RA, Giannelis EP. Lattice Model of Polymer Melt Intercalation in Organically-Modified Layered Silicates. Am Chem Soc. 1997;9297(95):7990-9.

Vaia RA, Giannelis EP. Polymer Melt Intercalation in Organically-Modified Layered Silicates: Model Predictions and Experiment. Macromolecules. 1997;30(25):8000-9.

Vaia R a, Ishii H, Giannelis EP. Synthesis and 
Properties of Two-Dimensional Nanostructures by Direct Intercalation of Polymer Melts in Layered Silicates. Chem Mater. 1993;5(16):1694-6.

Valandro SR, Poli AL, Neumann MG, Schmitt CC. Organomontmorillonite/poly(methyl methacrylate) nanocomposites prepared by in situ photopolymerization. Effect of the organoclay on the photooxidative degradation. Appl Clay Sci. 2013;85(1):19-24.

Venugopal G, Veetil JC, Raghavan N, Singh V, Kumar A, Mukkannan A. Nano-dynamic mechanical and thermal responses of single-walled carbon nanotubes reinforced polymer nanocomposite thinfilms. J Alloys Compd. 2016;688:454-9.

Vuluga Z, Panaitescu DM, Sanporean CG, Radovici C, Gabor R, Nicolae CA, et al. The effect of polystyrene blocks content and of type of elastomer blocks on the properties of block copolymer/ layered silicate nanocomposites. J Alloys Compd. 2014;616:569-76.

Wang MS, Pinnavaia TJ. Clay-Polymer Nanocomposites Formed from Acidic Derivatives of Montmorillonite and an Epoxy Resin. Chem Mater. 1994;6(4):468-74.

Weimer MW, Chen H, Giannelis EP, Sogah DY. Direct synthesis of dispersed nanocomposites by in situ living free radical polymerization using a silicate-anchored initiator. J Am Chem Soc. 1999;121(7):1615-6.

Wu J, Lerner MM. Structural, thermal, and electrical characterization of layered nanocomposites derived from sodium-montmorillonite and polyethers. Chem Mater. 1993;5(6):835-8.

Yano K, Usuki A, Okada A. Synthesis and properties of polyimide-clay hybrid films. J Polym Sci Part A Polym Chem. 1997 Aug;35(11):2289-94.

Yano K, Usuki A, Okada A, Kurauchi T, Kamigaito O. Synthesis and properties of polyimideclay hybrid. J Polym Sci Part A Polym Chem. 1993;31(10):2493-8.

Yenice Z, Tasdelen MA, Oral A, Guler C, Yagci Y. Poly(styrene-b-tetrahydrofuran)/clay nanocomposites by mechanistic transformation. J Polym Sci Part A Polym Chem. 2009;47(8):2190-7.

Zhang J, Gupta RK, Wilkie CA. Controlled silylation of montmorillonite and its polyethylene nanocomposites. Polymer. 2006;47(13):4537-43.
Zhang Y, Yang JH, Ellis TS, Shi J. Crystal structures and their effects on the properties of polyamide 12/clay and polyamide 6-polyamide 66/clay nanocomposites. J Appl Polym Sci. 2006;100(6):4782-94.

Zhou Q, Fan X, Xia C, Mays J, Advincula R. Living anionic surface initiated polymerization (SIP) of styrene clay surfaces. Chem Mater. 2001;13(8):2465-7.

Zhulina E, Singh C, Balazs AC. Attraction between surfaces in a polymer melt containing telechelic chains: Guidelines for controlling the surface separation in intercalated polymer-clay composites. Langmuir. 1999;15(11):3935-43.

Ziadeh M, Weiss S, Fischer B, Förster S, Altstädt V, Müller AHE, et al. Towards completely miscible PMMA nanocomposites reinforced by shear-stiff, nano-mica. J Colloid Interface Sci. 2014;425:14351. 